\title{
The effect of schooling on problem drinking: evidence from Australian twins
}

\author{
N. Zubanov ${ }^{\mathrm{a}, *}$, H. D. Webbink ${ }^{\mathrm{a}}$ and N. G. Martin ${ }^{\mathrm{b}}$ \\ ${ }^{a}$ Erasmus School of Economics, Erasmus University Rotterdam, \\ Burgemeester Oudlaan 50, 3062PA Rotterdam, The Netherlands \\ ${ }^{\mathrm{b}}$ Queensland Institute of Medical Research, Q 4029 Brisbane, Australia
}

\begin{abstract}
We relate differences in problem drinking symptoms within pairs of identical twins to their respective differences in years of schooling. Isolating in this way the influences of family background and genes, we find that an increase in schooling attainment results in a significantly lower incidence of problem drinking for men. Thus, an extra year of schooling reduces the number of health problems caused by drinking by 0.14 , and the probability of developing symptoms of Alcohol Dependence (AD) by 0.06 . This negative link is robust to a variety of modifications to the identifying assumptions underlying our statistical analysis. Socio-economic implications of our findings are discussed.
\end{abstract}

Keywords: problem drinking; education; twin studies; health

JEL Classification: I10; I20

\section{Introduction}

Problem drinking is among the top causes of poor health in the world, especially for men in high-income countries (see Lopez et al., 2006), costing noticeable fractions of national output. For instance, in Australia, where our data come from, the tangible costs of alcohol abuse (output loss, healthcare, crime) are estimated at $\mathrm{A} \$ 10.8 \mathrm{bn}$ per year (Collins and Lapsley, 2008, p. 5), or $1.2 \%$ of the country's Gross Domestic Product (GDP) (2005 estimate). In the UK and the US, the comparable costs as a fraction of GDP are even higher: $1.7 \%$ and $1.5 \%$, respectively. ${ }^{1}$ There are also less tangible costs in terms of socio-economic status, emotional well-being and safety. The 'health gradient' literature links problem drinking with education (Cutler and Lleras-Muney, 2006; Furnée et al., 2008), with several studies finding that more educated people consume less alcohol in ethanol equivalents (Baltagi and Griffin, 1995; Sharpe et al., 2001; Häkkinen et al., 2006). A niche within this literature focusses on excessive drinking. For instance, Kenkel (1991) and Cutler and Glaeser (2005) using data from US National Health Interview Surveys found that more educated people were less likely to report 'heavy drinking' defined as consuming three or more drinks on a single day. Other examples include studies on excessive

\footnotetext{
*Corresponding author. E mail: zubanov@ese.eur.nl

${ }^{1}$ The latest estimate of economic costs of alcohol abuse in the US, \$185.4 bn per year (Harwood, 2000), dates back to 1998. The estimate for the UK, 25.1 bn pounds sterling, is based on 2008 data presented in UK National Audit Office's report on the topic (NAO, 2008).
} 
drinking and alcohol-related problems by van Oers et al. (1999) and Droomers et al. (2004) among Dutch adults, both studies concluding that schooling is associated with significantly lower risk of excessive drinking, suffering health problems and psychological dependence on drink, especially for men.

Can this empirical evidence sustain the argument that promoting public education will help reduce problem drinking? The findings above, though informative, are not sufficient to establish a causal link between schooling and problem drinking that is necessary to justify educational interventions. In fact, these interventions will be ineffectual if the link is not causal but instead factors immune to policy, such as family background or genes, co-determine schooling attainment and problem drinking. To establish a causal link between the two, which is the ambition of this study, one needs a method to uncover variation in schooling that is demonstrably independent of these factors. One approach to do so is to use instruments to identify part of the variation in schooling which is not due to family or genes. An example of this approach in the problem drinking research is the study by Park and Kang (2008), who used availability of schools in the region of birth and the culture-induced parental preference towards the first son as instruments for individual schooling attainment. They found some evidence that schooling induces healthy lifestyle, but none that it reduces 'heavy drinking' defined as consuming alcohol more than five times a month.

Using instruments invites healthy criticism as to whether the variance in schooling explained by them is really exogenous. For instance, while it is reasonable to assume, as Park and Kang (2008) did, that the distribution of genetic characteristics in their sample is independent of local public sector provisions, it may be argued that households with higher demand for education will move to areas with better or more numerous schools. Convincing instruments being often hard to come by, an alternative to Park and Kang's (2008) approach is to use variation in schooling among individuals sharing the same genes and family background, such as identical twins. This is the approach we follow. A number of studies have used twins data to identify exogenous variation in schooling, looking at its effects on various socio-economic outcomes, such as earnings (Ashenfelter and Krueger, 1994; Miller et al., 1995; Bonjour et al., 2003), children's education (Behrman and Rosenzweig, 2002), and obesity (Webbink et al., 2010), to mention a few. The studies by Heath et al. (1997) and Knopik et al. (2004) on genetic and environmental influences on Alcohol Dependence (AD), in which schooling is used as one of the controls, belong within this research tradition. Encouragingly, both studies found that university-educated men were about $40 \%$ less likely to have developed AD than the men without a high-school diploma (no significant effects were reported for female twins). Our study design is similar to theirs, except that we address the issue of measurement error in schooling as well, implementing one of Ashenfelter and Krueger's (1994) instrumental variable estimators to correct for measurement error in our schooling data, which presence we detect by comparing answers of the same individual given in different periods of time.

To preview our findings, while not affecting alcohol intake, schooling is negatively linked to a variety of problem drinking symptoms reported by men. (No consistently significant results were found for women.) For instance, an extra year of schooling reduces the likelihood of $\mathrm{AD}$ by $6 \%$, and the number of health problems caused by drinking by 0.14 . Relative to these indicators' variability in our sample (the SDs are 0.44 for AD, 0.50 for health problems), these are significant reductions. Our findings are robust to the inclusion of birth weight and personality, the factors which affect both schooling and problem drinking, as controls. More importantly, our results remain when we restrict our sample to twins who had completed their education before starting to drink alcohol, which implies that they are not driven by possible reverse causality between problem drinking and schooling. There is also some evidence for the effects of schooling to be stronger for twins with a family history of problem drinking, and for secondary schooling to be more important in its effect on problem drinking than further education.

Interpreting our findings, it is important to heed the limitations of our study, common to much of the literature on identical twins, of which the biggest are the following two. The first is the assumption that schooling differences between identical twins are exogenous to the factors co-determining schooling and problem drinking. While small differences in years of schooling (for example, when one twin attains a bachelor's degree and the other graduates with a master's) may indeed be random, this assumption becomes increasingly demanding for larger differences. To try to weaken the strength of this assumption somewhat, we repeat our analysis on the subsample in which within-twin differences in schooling do not exceed 3 years, obtaining similar results as on the entire sample, albeit less precisely estimated. The second limitation is that we cannot account for the presence of 'peer effects', that is, twins' drinking 
behaviours affecting one another. To try to infer their existence, we exploit the information on the frequency of twins' seeing each other and repeat our main analysis on the subsamples of twins being in contact with each other more and less frequently than once a year. We find that our main results for men do not depend on frequency of contacts. Given the robustness of our results, we are inclined to interpret them as evidence for causal effect of schooling, admitting, however, that we cannot fully exclude other explanations behind them, such as starting to drink and leaving school upon meeting wrong friends or reducing own drinking seeing a bad example of an alcoholic co-twin.

Its limitations notwithstanding, our study contributes to the problem drinking niche in the health gradient literature by carefully addressing the issue of endogenous schooling, and by presenting a plausible research design to try to establish an exogenous, 'natural experiment'-type, source of variation in schooling, while pointing to the challenges to this endeavour. We bring various measures of problem drinking developed in medical studies together with our own indicators focussing on its particular aspects such as health problems (Section II). As a methodological contribution, we bring the problem drinking research closer to modern economics/econometrics agenda by addressing the issues of measurement error in schooling (Section II) and reverse causality between schooling and drinking, as well as by examining heterogeneity in the effects of schooling for different population groups (Section III). These issues have important implications not only for the consistency of our findings, but also for drawing wider implications from our study, which we sketch in the concluding Section IV.

\section{Data and Method}

\section{Sources of data}

Our data come from the Australian Twin Register and include three survey waves of the same group of Australian twins, labelled Canberra (collected in 1980-1982), Alcohol-1 (1988-1989) and SemiStructured Assessment for the Genetics of Alcoholism (SSAGA) collected in 1993. Canberra and Alcohol-1 contain a large number of questions covering, among schooling and drinking patterns, the age when the respondent started to drink alcohol, biometric data, health, family, employment, personality and socio-economic background.
Alcohol-1 also includes questions on individual health and personal and behavioural problems perceived to be caused by drinking. SSAGA is the source of data on the AD indicator, which we compute based on the work of Knopik et al. (2004), as well as on personality characteristics. Our key dataset is Alcohol-1 because it contains the most accurate and recent schooling data available to us. It is well suited for our inquiry because the minimum respondent age in Alcohol-1 is 25 (the average is 42, and the median age is 40), so that most of the subjects would have completed their schooling and have some history of drinking alcohol by the time of the survey. This does not, of course rule out a possible reverse causality between schooling and problem drinking, which we address later in the article. A total of 1149 complete pairs of identical twins participated in all three waves (down from 1798 in Canberrra), of whom between 776 and 431 (depending on the indicator) had complete data required for our analysis.

\section{Schooling}

In the original data, schooling is recorded in levels (less than 7 years at school; 8-10 years; $10-12$ years or apprenticeship or trade certificate; technical or teacher's college; university; post-graduate degree), which we convert into, respectively, 5, 9, 11.5, 13, 15 and 17 years of schooling, as was done in Miller et al. (1995), who also used these data. The median schooling is 11.5 years for both sexes. The average years of schooling are 12.6 for men and 11.2 for women, slightly higher than the averages for the general population, which can be explained by more educated people being more likely to participate in the surveys. Schooling attainment varies widely between individuals: its SD is 2.5 years for both sexes. Yet, much of this variation is between twin pairs, since $51 \%$ of male and $63 \%$ of female participants report the same years of schooling as their identical twin. Among the pairs with different years of schooling, the average difference is about 2.7 years for both sexes; differences in excess of 4 years are very rare $(<3 \%$ of cases).

Closer inspection reveals high intra-pair correlation between the twins' years of schooling: 0.81 for identical and 0.59 for fraternal twins (not part of our working sample), similar to the estimates reported in Behrman and Taubman (1989), 0.75 and 0.55. The higher correlation for identical twins suggests an important role of genetic endowments in determining educational attainment. Performing a standard genetic decomposition of variance in schooling, we learn that genes account for $62 \%$ of its variation 
Table 1. Alcohol intake by gender

\begin{tabular}{|c|c|c|c|c|c|c|c|c|}
\hline \multirow[b]{2}{*}{ Variable } & \multicolumn{4}{|l|}{ Men } & \multicolumn{4}{|l|}{ Women } \\
\hline & Observations & Mean & SD & $\begin{array}{l}\text { Correlation } \\
\text { with } \\
\text { schooling }\end{array}$ & Observations & Mean & SD & $\begin{array}{l}\text { Correlation } \\
\text { with } \\
\text { schooling }\end{array}$ \\
\hline $\begin{array}{l}\text { Number of drinks last } \\
\text { week in } 1988\end{array}$ & 1134 & 8.704 & 13.134 & 0.082 & 2462 & 4.075 & 7.042 & 0.058 \\
\hline Same in 1980 & 1134 & 13.525 & 18.028 & 0.089 & 2462 & 5.148 & 8.518 & 0.032 \\
\hline $\begin{array}{l}\text { Maximum number of } \\
\text { drinks per day on } \\
\text { typical week }\end{array}$ & 1119 & 3.535 & 4.062 & 0.054 & 2452 & 1.986 & 2.490 & 0.063 \\
\hline $\begin{array}{l}\text { Maximum number of } \\
\text { drinks per day ever }\end{array}$ & 1128 & 8.759 & 10.228 & 0.026 & 2454 & 4.115 & 4.982 & 0.126 \\
\hline
\end{tabular}

between individuals. ${ }^{2}$ Thus, genes appear to play an important role in schooling attainment, and therefore estimating causal effects of schooling requires isolating their influence, which we do by exploiting the variation in schooling within pairs of identical twins.

Another interesting feature of the years of schooling variable is the presence of measurement error in it. Comparing the responses of the same individuals in the Canberra (1980) and Alcohol-1 (1988) samples reveals that $14.5 \%$ report less schooling in 1988 than in 1980. In fact, the correlation between own- and twin-reported schooling for the same individual (the 'reliability ratio') in our data is about 0.8 for men and 0.85 for women, close to the 0.9 reported by Ashenfelter and Krueger (1994, p. 1160) for US twins schooling, implying that $20 \%$ of the observed variance in schooling for men, and $15 \%$ for women, is due to measurement error. Measurement error in the explanatory variable causes its regression estimate to be biased towards zero, thus underestimating its effect. We deal with the measurement error issue in our analysis by instrumenting own-reported with twinreported schooling as was done by Ashenfelter and Krueger (1994).

\section{Alcohol intake}

We calculate the following measures of alcohol intake: the number of drinks consumed during the week preceding the day of the interview; ${ }^{3}$ the maximum number of drinks had on a day of a typical week; and the maximum number of drinks ever had in a single day. Table 1 reports descriptive statistics of the intake variables, separately for men and women, as well as their correlations with years of schooling. The average weekly intake is 8.7 drinks for men and 4.1 drinks for women. A decrease in average alcohol intake in 1988 compared to 1980 is noticeable, especially for men, and can be partly explained through the life-cycle pattern in alcohol intake, ${ }^{4}$ and partly through secular trends in alcohol consumption. Weekly intake is uneven: men consume $40 \%(=3.5 / 8.7)$ of their weekly intake on a single day; this ratio is even higher, at $50 \%$, for women. Excessive drinking is noticeable, with the maximum daily intake ever in a lifetime comparable to the total intake for the whole typical week. There is a negative correlation between alcohol intake and schooling for men and positive for women.

\section{Problem drinking indicators}

Although alcohol intake, regular or excessive, is perhaps the most objective measure of individual exposure to potentially harmful effects of alcohol, it is only one of the many characteristics of

\footnotetext{
${ }^{2}$ Suppose the total variance in schooling $\left(\sigma^{2}\right)$ is the sum of three independent components: genetic $\left(\sigma_{g}^{2}\right)$, family $\left(\sigma_{f}^{2}\right)$ and environmental $\left(\sigma_{e}^{2}\right)$. For identical twins, who share the genetic and family components, the share of the common component in the total variance in schooling is $\frac{\sigma_{g}^{2}+\sigma_{f}^{2}}{\sigma^{2}}$, which is equal to the squared correlation coefficient between years of schooling of identical twins, $0.81^{2} \quad 0.66$. For fraternal twins, who share the family component and half the genes, the common component accounts for $\frac{0.5 \sigma_{g}^{2}+\sigma_{f}^{2}}{\sigma^{2}} 0.59^{2} \quad 0.35$. So, the fraction in the total variance in schooling due to genes is $\frac{\sigma_{g}^{2}}{\sigma^{2}}$ $2 \times\left(\begin{array}{ll}0.66 & 0.35\end{array}\right)^{\sigma^{2}} 0.62$.

${ }^{3}$ To ensure comparability of observations taken from different people at different points in time, in the regression analysis to follow, we adjust weekly alcohol intake for seasonality. We calculate the seasonal component of weekly intake by regressing the intake data on the set of dummy variables representing the month when the observation was recorded, and then subtract this component from the actual intake.

${ }^{4}$ Regressing weekly alcohol intake on age and other controls (results available upon request) reveals that the intake decreases by 0.1 drinks for men and 0.035 drinks for women with every extra year of age.
} 
Table 2. Incidence of symptoms of problem drinking

\begin{tabular}{|c|c|c|c|c|}
\hline \multirow[b]{2}{*}{ Variable } & \multicolumn{2}{|l|}{ Men } & \multicolumn{2}{|l|}{ Women } \\
\hline & Observations & Mean & Observations & Mean \\
\hline $\begin{array}{l}\text { How often do you have an alcoholic drink? } \\
\qquad \begin{array}{l}\text { (1 monthly or less, } 2 \quad 24 \text { times a month, } \\
323 \text { times a week, } 4 \quad 4+\text { times a week })\end{array}\end{array}$ & 1959 & 2.337 & 3395 & 1.912 \\
\hline $\begin{array}{l}\text { How many alcoholic drinks do you have on a typical day? } \\
\quad(1 \quad 12,234,356,479,510+)\end{array}$ & 1633 & 1.508 & 2677 & 1.226 \\
\hline \multicolumn{5}{|l|}{ Have you ever... ( 0 no, 1 yes $)$} \\
\hline Felt you should cut down drinking? & 1798 & 0.709 & 3174 & 0.534 \\
\hline Tried, but failed, to cut down drinking? & 1766 & 0.061 & 3131 & 0.024 \\
\hline Heard people objecting to your drinking? & 1765 & 0.364 & 3132 & 0.121 \\
\hline Felt bad or guilty about your drinking? & 1778 & 0.357 & 3150 & 0.218 \\
\hline Had a drink first thing in the morning? & 1803 & 0.090 & 3221 & 0.016 \\
\hline Been drinking heavily for 2 or more days in a row? & 1389 & 0.176 & 1961 & 0.044 \\
\hline Neglected your usual responsibilities drinking $2+$ days? & 1764 & 0.090 & 3142 & 0.021 \\
\hline Had problems with friends and/or family because of drinking? & 1422 & 0.255 & 1978 & 0.084 \\
\hline Got into trouble at work because of drinking? & 1372 & 0.095 & 1958 & 0.027 \\
\hline Got into trouble because of drunk driving? & 1414 & 0.170 & 1964 & 0.031 \\
\hline Injured yourself or others when you were drinking? & 1411 & 0.251 & 1967 & 0.059 \\
\hline Approached anyone for help about your drinking? & 1489 & 0.042 & 2114 & 0.020 \\
\hline Been treated for a drinking problem? & 1353 & 0.027 & 1951 & 0.016 \\
\hline $\begin{array}{l}\text { Had delirium tremens, severe shaking or hallucinations } \\
\text { after heavy drinking? }\end{array}$ & 1482 & 0.047 & 2113 & 0.015 \\
\hline Experienced other health problems because of drinking & 1382 & 0.200 & 1966 & 0.101 \\
\hline
\end{tabular}

problem drinking that our data allow us to calculate. Table 2 reports the incidence of various symptoms of problem drinking by gender. An average man drinks alcohol 2-4 times a month to 2-3 times a week, consuming between 1-2 and 3-4 drinks on a typical day (not weekend). An average woman takes 1-2 drinks a day 2-4 times a month. These statistics do not contradict the average alcohol intake reported in the previous section, since much of the weekly alcohol intake falls on one day which is likely to be weekend, not a typical day.

Turning from the usual drinking patterns to the events happened at least once in a lifetime, $71 \%$ of men and $53 \%$ of women felt at some point that they should cut down their drinking. This statistic is potentially ambiguous, because the threshold from which drinking becomes problematic for the individual in question varies, and it may be misleading if this threshold is positively related to the amount of alcohol usually consumed. Yet, drinking is often regarded as excessive not only by the individual in question but also by those around him. Thus, 36\% $(12 \%)$ of men (women) reported having heard other people objecting to their drinking, 36\% (22\%) felt bad or guilty about their drinking; and $24 \%(8 \%)$ admitted both.

Recognizing own drinking as problematic does not always lead to reducing or stopping it completely. Thus, a number of people report symptoms of addiction to drink: trying, but failing, to cut down drinking ( $6 \%$ of men and $2 \%$ of women), drinking first thing in the morning ( $9 \%$ and $2 \%)$, and drinking heavily for more than 2 days in a row $(18 \%$ and $4 \%$ ). Statistics in Table 2 also reveal that many people see their drinking as the reason behind a variety of personal problems, such as problems with family or friends $(26 \%$ and $8 \%)$, drunk driving $(17 \%$ and $3 \%)$, health $(20 \%$ and $10 \%)$, to name a few. The answers form a coherent picture, where alcohol intake is positively correlated with both inability to stop or reduce drinking and health and personal problems.

This variety of characteristics allows us to construct more aggregate measures of problem drinking and thus link our study to others operating with these measures. The most popular measure is the AD indicator used, among others, in Slutske et al. (2002) and Knopik et al. (2004). This indicator is based on American Psychiatric Association's manual of mental disorders (APA, 2000) which lists nine symptoms currently experienced by a respondent: (i) drinking more, and over longer periods of time, than intended; (ii) wanting but not being able to stop/cut-down drinking; (iii) long time spent drinking; (iv) withdrawal symptoms that prevent fulfilling major obligations (e.g. work, school, etc.); (v) giving up important activities because of drinking; (vi) carrying on drinking in the knowledge of its adverse effects; 
Table 3. Aggregate problem drinking indicators by gender

\begin{tabular}{|c|c|c|c|c|c|c|c|c|}
\hline \multirow[b]{2}{*}{ Indicator } & \multicolumn{4}{|l|}{ Men } & \multicolumn{4}{|l|}{ Women } \\
\hline & Observations & Mean & SD & $\begin{array}{l}\text { Correlation } \\
\text { with } \\
\text { schooling }\end{array}$ & Observations & Mean & SD & $\begin{array}{l}\text { Correlation } \\
\text { with } \\
\text { schooling }\end{array}$ \\
\hline AD & 652 & 0.253 & 0.435 & 0.065 & 1131 & 0.081 & 0.273 & 0.046 \\
\hline Five shot & 724 & 4.349 & 2.823 & 0.091 & 1417 & 2.863 & 2.168 & 0.023 \\
\hline CAGE & 802 & 1.421 & 1.207 & 0.018 & 1775 & 0.821 & 0.958 & 0.068 \\
\hline $\begin{array}{l}\text { Inability to reduce/stop } \\
\text { drinking }\end{array}$ & 602 & 0.704 & 0.949 & 0.040 & 1034 & 0.366 & 0.653 & 0.021 \\
\hline $\begin{array}{l}\text { Behavioural problems } \\
\text { caused by drinking }\end{array}$ & 600 & 1.033 & 1.404 & 0.116 & 1039 & 0.339 & 0.836 & 0.025 \\
\hline $\begin{array}{l}\text { Health problems } \\
\text { caused by drinking }\end{array}$ & 588 & 0.221 & 0.504 & 0.003 & 1026 & 0.094 & 0.335 & 0.009 \\
\hline
\end{tabular}

(vii) tolerance to alcohol (larger intake required to get drunk than when started); (viii) experiencing withdrawal symptoms (e.g. shaking or delirium tremens); (ix) drinking to relieve withdrawal symptoms. An individual is diagnosed positively for $\mathrm{AD}$ (i.e. $\mathrm{AD}=1$ ) if he or she has three or more of the above symptoms.

We also calculate the five-shot and CAGE (the acronym for cut down, annoy, guilty, 'eye opener') indicators which have been applied in medical practice for diagnosing an alcohol problem (Mayfield et al., 1974; Seppä et al., 1998), as well as indicators focussing on particular aspects of problem drinking. ${ }^{5}$ The five-shot indicator is based on the answers to the following questions:

- how often do you have a drink containing alcohol? ('never' $=0$ points, 'monthly or less' $=1$ point, ' $2-4$ times a month' $=2$ points, ' $2-3$ times a week' $=3$ points, ' $4+$ times a week' $=4$ points);

- how many drinks containing alcohol do you have on a typical day? (' $1-2$ ' $=0, ' 3-4$ ' $=1,{ }^{\prime} 5-6$ ' $=2$, $' 7-9$ ' $=3$, ' $10+'=4)$;

- have people ever objected to your drinking? ('no' $=0$, 'yes' $=2$ );

- have you ever felt bad/guilty about your drinking ('no' =0, 'yes' = 2);

- have you ever had a drink first thing in the morning? ('no' $=0$, 'yes' $=2$ ).

The CAGE indicator includes the last three questions of five-shot plus the question 'have you ever thought you should cut down on drinking?', each 'yes' answer carrying one point.

The indicators focussing on particular aspects of problem drinking are calculated as the sum of the answers ('yes' $=1$, 'no' $=0$ ) to their underlying questions. Their content is given below:

(1) Inability to reduce/stop drinking: Have you ever... (1) tried but failed to cut-down drinking; (2) had a drink first thing in the morning; (3) drank heavily for 2 or more days in a row; (4) approached someone for help about drinking; (5) felt bad or guilty about your drinking.

(2) Behavioural problems caused by drinking: (1) heard people objecting to your drinking; (2) neglected your usual responsibilities because of drinking for 2 days or more; (3) had problems with friends and/or family because of drinking; (4) had problems at work/ study because of drinking; (5) got into trouble because of drunk driving; (6) injured yourself or others while drinking.

(3) Health problems caused by drinking: (1) received treatment for a drink problem; (2) had delirium tremens, severe shaking or hallucinations after heavy drinking; (3) had other health problems because of drinking.

Table 3 shows descriptive statistics on our aggregate problem drinking indicators. $25 \%$ of men and $8 \%$ of women in our sample would be diagnosed with $\mathrm{AD}(\mathrm{AD}=1)$. These rates seem high compared to more recent survey data on $\mathrm{AD}$ in Australia

\footnotetext{
${ }^{5}$ Another well known test is the Alcohol Use Disorders Identification Test (AUDIT) (Babor et al., 2001). This test includes 10 questions concerning the amount, frequency of alcohol consumed, drinking patterns, (in)ability to stop drinking, its psychological and behavioural consequences. Data limitations prevent us from implementing it in full. However, the five shot test, a shorter version of it, is almost as accurate.
} 
(2007, 5.2\% men, $2.4 \%$ women), ${ }^{6}$ the UK (2007, 9\% men, $4 \%$ women $)^{7}$ and US $(2001,6.9 \%$ men, $2.6 \%$ women $),{ }^{8}$ but there is a lot of variance in the measures used in different surveys, which makes comparisons difficult. The average incidence of inability to stop/reduce drinking at least on one occasion in their lifetime is 0.7 for men and 0.37 for women. Further, an average man had one behavioural problem due to drinking at least once in his life, and an average woman just over a third. There is also a relatively high incidence of health problems perceived to be caused by drinking: 0.22 for men and 0.09 for women. As with alcohol intake, there is mostly a negative link between the indicator scores and years of schooling for men and positive (though weak) for women.

\section{Controls}

To account for other influences on problem drinking which may also be correlated with schooling, we use twins' birth weight and personality as controls. These variables have been shown to affect problem drinking and education attainment. Birth weight has been linked with problem drinking symptoms in adult males (Knop et al., 2003) and also with several personal and labour market outcomes, including schooling attainment (Black et al., 2007). As for personality, Slutske et al. (2002) found behavioural undercontrol to contribute to the risk of developing AD, while Maqsud (1993) finds psychoticism (a personality trait underlying behavioural undercontrol) to be negatively correlated with academic attainment. It must be noted that personality is a potentially endogenous control, since alcoholism may in turn affect personality or co-occur with various personality disorders (Preuss et al., 2009), and if so, the specification with the personality variables included would underestimate the effect of schooling.

We follow Slutske et al. (2002) in calculating personality indicators based on the Tridimensional and Eysenck Personality Questionnaires using the SSAGA (1993) sample. A principal component analysis on the novelty seeking, harm avoidance, reward dependence, extraversion, neuroticism, psychoticism and lie scores yields three dimensions of personality, together explaining $70 \%$ of the total variance in the individual scores. The first dimension, labelled 'Negative Emotionality' (NE), explains 32\% of the total variance in the scores and is associated with harm avoidance and neuroticism. High scores on this dimension point to high levels of anxiety, insecurity, mood changes and general unhappiness. The second dimension, 'Positive Emotionality' (PE), is mostly made up of reward dependence and extraversion and explains $17 \%$. High scores on this dimension are earned by lively, friendly and outgoing people. The third dimension, 'Behavioural Undercontrol' (BU), encapsulating novelty seeking, psychoticism and propensity to lie and explaining the remaining $21 \%$ of the total variation in personality dimensions, is associated with implusiveness, thrill seeking, rebelliousness and lack of responsibility.

\section{Estimation issues}

The problem with the causal interpretation of regressions of problem drinking on schooling is that both these variables may be co-determined by unobservables such as genes or family background. Indeed, we have seen in Section II that genetic differences account for a large part of the variation in schooling attainment. However, identical twin pair controls will help reveal the causal effect of schooling under certain assumptions as we now explain.

Suppose that a problem drinking indicator of interest $y$ is a linear function ${ }^{9}$ of years of schooling $(s)$, observed controls (vector $\mathbf{x}$ ) and the error term $u$ which summarizes other, unobserved, determinants of $y$

$$
y_{i j}=\beta s_{i j}+\mathbf{x}_{i j} \gamma+u_{i j}
$$

where $i=1,2, \ldots, N$ is the twin pair index, $j=1,2$ is the individual twin index. Genes co-determining problem drinking and schooling attainment will induce a correlation between schooling and the error term in Equation 1, resulting in a biased estimate of the effect of schooling. We can remove this correlation by assuming that $u_{i j}$ can be expressed as the sum of two components: the component common to both twins $\left(\alpha_{i}\right)$, such as genes or/and family characteristics, and the individual error term, $e_{i j}$. The term $\alpha_{i}$ can then be removed from Equation 1 by

\footnotetext{
${ }^{6}$ Source: Australian Bureau of Statistics, National Survey of Mental Health (2007). Available at http://www.abs.gov.au/ AUSSTATS/abs@.nsf/DetailsPage/4326.02007?OpenDocument (accessed 6 September 2011).

${ }^{7}$ Source: NHS Statistics on Alcohol: England (2009). Available at http://www.ic.nhs.uk/statistics and data collections/health and lifestyles/alcohol (accessed 6 September 2011).

${ }^{8}$ Source: US National Institute on Alcohol Abuse and Alcoholism. Available at http://www.niaaa.nih.gov/Resources/ DatabaseResources/QuickFacts/AlcoholDependence/abusdep1.htm (accessed 6 September 2011).

${ }^{9}$ We have tried to relax the linearity assumption by estimating a Poisson regression model with twin fixed effects (results are available upon request). However, our findings were not much different from what we report here.
} 
taking within twin pair differences. Estimating (1) in differences,

$$
\Delta y_{i}=y_{i 1}-y_{i 2}=\beta \Delta s_{i}+\Delta \mathbf{x}_{i} \gamma+\Delta e_{i}
$$

with the Ordinary Least Squares (OLS) method yields an unbiased estimate for $\beta$ assuming (i) that both twins share the same $\alpha$, and (ii) that $\alpha$ is the only source of endogeneity in the years of schooling variable. To satisfy the first assumption, we concentrate on identical twins who share genes as well as family background. The second, requiring that the error term $\Delta e_{i}$ in Equation 2 be uncorrelated with twin differences in schooling, $\Delta s_{i}$, remains our identifying assumption. To test the sensitivity of our results to the strength of this assumption, we will later concentrate on the twin pairs in which differences in schooling are small and thus are more likely to be exogenous.

The other estimation issue that we address in this study is measurement error in schooling. Suppose the true schooling of twin $j$ in pair $i, s_{i j}$, is measured by self-reported schooling, $s_{i j}^{\prime}$

$$
s_{i j}^{\prime}=s_{i j}+\epsilon_{i j}
$$

where $\epsilon_{i j}$ is the unobserved measurement error with mean zero and variance $\sigma_{j}^{2}$. Thus $\Delta s_{i}=\Delta s_{i}^{\prime}-\Delta \epsilon_{i}$. Substituting the latter expression for $\Delta s_{i}$ in Equation 2 , resulting in

$$
\Delta y_{i}=\beta \Delta s_{i}^{\prime}+\Delta \mathbf{x}_{i} \gamma+\Delta e_{i}-\beta \Delta \epsilon_{i}
$$

we see that applying OLS to Equation 4 will produce a downward-biased estimate for $\beta$ because $\Delta s_{i}^{\prime}$ and $\Delta \epsilon_{i}$ are correlated by construction (see Equation 3) and therefore $\operatorname{cov}\left(\Delta s_{i}^{\prime}, \Delta e_{i}-\beta \Delta \epsilon_{i}\right)=-\beta\left(\sigma_{1}^{2}+\sigma_{2}^{2}+\right.$ $\left.2 \operatorname{cov}\left(\epsilon_{i 1}, \epsilon_{i 2}\right)\right)<0$. To remove this bias, Ashenfelter and Krueger (1994) propose instrumenting ownreported with twin-reported schooling. There are two approaches to implementing this instrumentation in the equation in differences (4): (i) instrument the difference in own-reported schooling with the difference in twin-reported schooling; and (ii) instrument the difference in schooling as reported by one twin with the difference in schooling as reported by the other twin. We take the second approach because, unlike the first, it is robust to the presence of individual-specific measurement error. ${ }^{10}$ The correlation between own and twin-reported schooling is quite high, suggesting that twin-reported schooling is a good choice of instrument.

\section{Results}

Table 4 reports the estimated effects of one extra year of schooling on alcohol intake and problem drinking outcomes. We run our regressions separately for men and women in the following five specifications: (1) basic, where the outcome variable is regressed on years of schooling only (Equation 1 without controls); (2) twin differences (Equation 2 without controls); (3) same as (2) with schooling instrumented to correct for measurement error; (4) same as (3) with added controls; and (5) same as (4) estimated on the subsample of twins who had an alcoholic drink within a year before the date of the interview. To ensure comparability of estimates, all specifications for a given dependent variable, except (5) are applied on the same sample.

Some comments on our estimation procedure are in order. Even though most twins report the same years of schooling as their co-twin, about $30 \%$ of female and $45 \%$ of male twin pairs differ in schooling, providing sufficient variation to identify the effects of our interest. Taking twin differences (column 2) does change the estimates, but in a way suggesting that the unobservables affecting both schooling attainment and problem drinking outcomes

${ }^{10}$ To see this important difference between the two instrumentation approaches, denote $s_{i, m}^{n} \quad s_{i}^{n}+v_{i, m}^{n}$ the years of schooling of twin $n$ as reported by twin $m$ in twin pair $i$, where $s_{i}^{n}$ is true schooling and $v_{i, m}^{n}$ is the measurement error. Then, for every twin pair, four measures of difference in schooling can be specified

$$
\begin{array}{cccccc}
\Delta s_{i}^{\prime} & s_{i, 1}^{1} & s_{i, 2}^{2} & s_{i}^{1} & s_{i}^{2}+v_{i, 1}^{1} & v_{i, 2}^{2} \\
\Delta s_{i}^{\prime \prime} & s_{i, 2}^{1} & s_{i, 1}^{2} & s_{i}^{1} & s_{i}^{2}+v_{i, 2}^{1} & v_{i, 1}^{2} \\
\Delta s_{i}^{*} & s_{i, 1}^{1} & s_{i, 1}^{2} & s_{i}^{1} & s_{i}^{2}+v_{i, 1}^{1} & v_{i, 1}^{2} \\
\Delta s_{i}^{* *} & s_{i, 2}^{1} & s_{i, 2}^{2} & s_{i}^{1} & s_{i}^{2}+v_{i, 2}^{1} & v_{i, 2}^{2}
\end{array}
$$

Two pairs of variables satisfy the requirements for valid instruments: $\Delta s^{\prime}$ and $\Delta s^{\prime \prime}$, and $\Delta s^{*}$ and $\Delta s^{* *}$ (the other pairs contain common measurement errors). However, instrumenting $\Delta s^{\prime}$ with $\Delta s^{\prime \prime}$ (in words: own reported schooling with twin reported schooling) assumes that the measurement errors $v_{i, 1}^{1} \quad v_{i, 2}^{2}$ and $v_{i, 2}^{1} \quad v_{i, 1}^{2}$ are uncorrelated, which assumption will fail if there is an individual specific component $v_{i, m}$ in each of the four measurement errors $v_{i, m}^{n}$, because then $\operatorname{cov}\left(v_{i, 1}^{1} \quad v_{i, 2}^{2}, v_{i, 2}^{1} \quad v_{i, 1}^{2}\right) \quad \operatorname{var}\left(v_{i, 1}\right)+\operatorname{var}\left(v_{i, 2}\right) \quad 2 \operatorname{cov}\left(v_{i, 1}, v_{i, 2}\right)$. On the other hand, instrumenting $\Delta s^{*}$ with $\Delta s^{* * *}$ (the difference in schooling as reported by one twin with the same reported by the other twin) is robust to $v_{i, m}$ because taking the difference between the own and twin schooling as reported by the same twin will cancels $v_{i, m}$ out. 


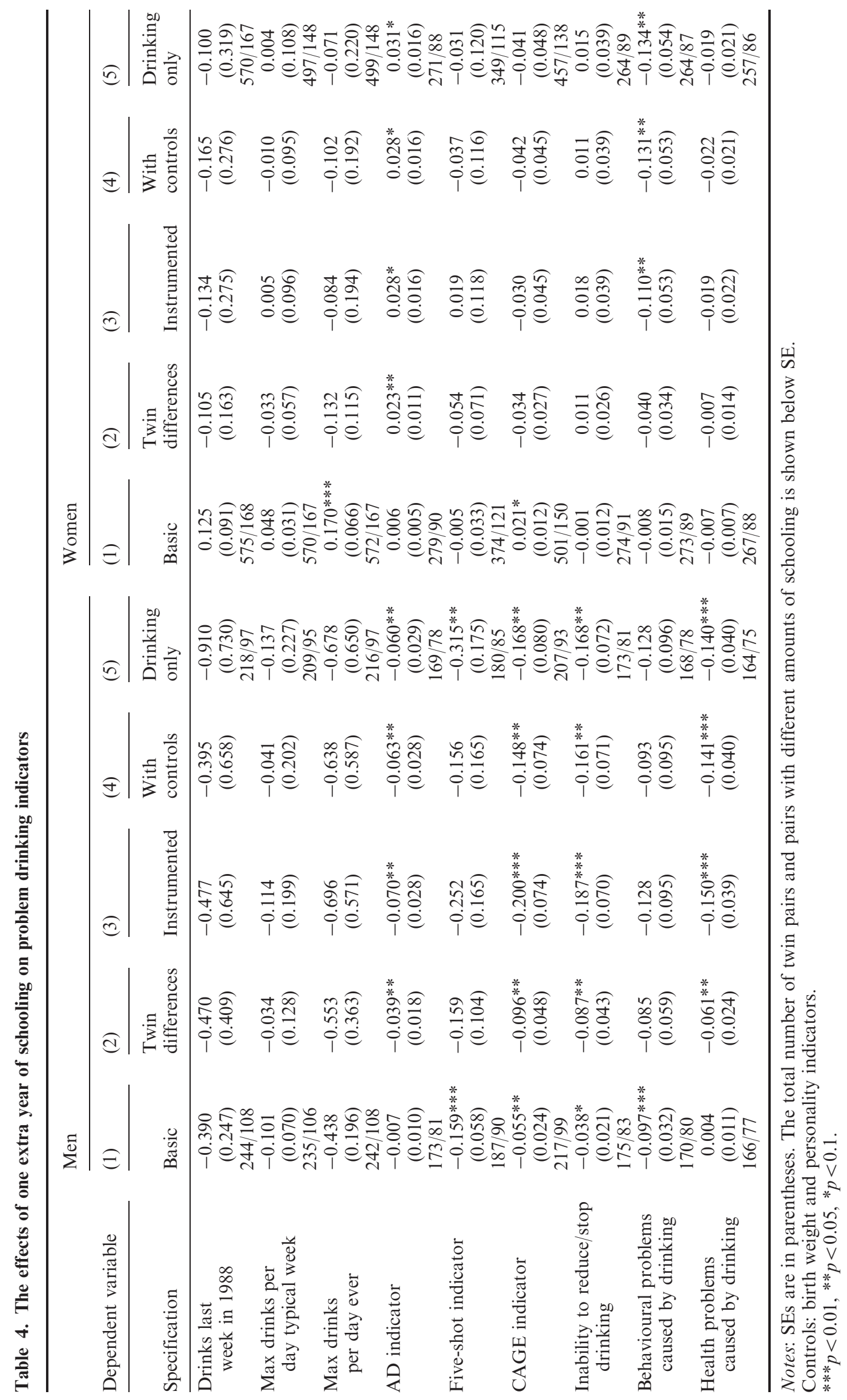


are such that more educated twin pairs are also more likely to develop problem drinking symptoms. Instrumenting own-reported schooling with twin-reported (column 3) generally increases the magnitude of the estimates, as expected given the measurement error in our schooling data. This increase in magnitude is larger for men than for women, since the reliability of men's own-reported schooling is lower. The inclusion of controls (column 4) reduces the magnitude of the estimated effects of schooling on problem drinking indicators for men and increases them for women, though - reassuringly - not by a large margin for both sexes, suggesting that they do not play any important role in shaping the link of our main interest. Of these controls, the most important is the personality dimension labelled 'BU' which is often positively linked with problem drinking for both sexes. Birth weight is unimportant for men but is often negatively linked with women's problem drinking symptoms. Restricting the sample to active drinkers (column 5) tends to increase the magnitude of the estimates, since the effect of schooling for nondrinkers is by definition zero, although the differences between columns (4)'s and (5)'s estimates are small. Our preferred specification, on which we base our inferences, is (5). Although it contains potentially endogenous personality controls which can lead to underestimation of schooling effects, we believe it is safe to include them and work with conservative estimates of schooling effects.

The estimates of the effect of schooling on alcohol intake are consistently insignificant for both sexes, and also small compared to their averages and SDs. Where schooling is important is problem drinking indicators. Thus, an extra year of schooling reduces the probability of developing $\mathrm{AD}$ by men by $6 \%$ (column 5). Schooling has negative effects on some other indicators as well, reducing the CAGE and inability to stop indicators by just under 0.17 with an extra year, and the health problem indicator by 0.14 . For women, schooling significantly reduces the number of behavioural problems, by 0.13 with an extra year and, intriguingly, increases the likelihood of $\mathrm{AD}$ by about $3 \%$, although this effect is barely significant and is small relative to the size and variation of the $\mathrm{AD}$ indicator among female twins. The differences between estimates for schooling on the male and female samples are statistically significant at less than 10\% level for all indicators except
Table 5. Magnitudes of the effect of one extra year of schooling relative to sample variability of problem drinking indicators

\begin{tabular}{|c|c|c|c|}
\hline Indicator & $\begin{array}{l}\text { Sample } \\
\text { SD }\end{array}$ & $\begin{array}{l}\text { Point } \\
\text { estimate }\end{array}$ & $\begin{array}{l}\text { Relative } \\
\text { reduction } \\
(\%)\end{array}$ \\
\hline AD indicator & 0.435 & $0.060 * *$ & 13.8 \\
\hline CAGE Men & 1.207 & $0.168 * *$ & 13.9 \\
\hline $\begin{array}{l}\text { Inability to stop/reduce } \\
\text { drinking Men }\end{array}$ & 0.949 & $0.168 * *$ & 17.7 \\
\hline $\begin{array}{l}\text { Health problems caused } \\
\text { by drinking Men }\end{array}$ & 0.504 & $0.140 * * *$ & 27.8 \\
\hline $\begin{array}{l}\text { Behavioural } \\
\text { problems }\end{array}$ & 0.836 & $0.134 * *$ & 16 \\
\hline
\end{tabular}

Note: $* * * p<0.01, * * p<0.05$.

behavioural problems in which case the estimates for men and women are similar. ${ }^{11}$ The gender differences in the effects of schooling will persist in the extensions and robustness checks to our main results we perform in the following sections.

To illustrate the importance of the effects of an extra year of schooling relative to the problem drinking symptoms' variability, we express the significant estimates in terms of the sample SDs of the respective dependent variables. Table 5 shows that these reductions may be rather large, up to a quarter of SD (health problems), suggesting that educational interventions may play an important role in preventing the losses due to problem drinking.

\section{The life cycle of alcoholism}

We have seen earlier in the article (Table 1) that the average alcohol intake reported in 1988 is lower than in 1980, a tendency suggesting the presence of a lifecycle pattern in the intake and, by implication, alcoholism, on which we concentrate in this section. Life-cycle patterns in alcoholism were reported in Vaillant's (1995) authoritative study on the topic, in which he tracked two samples of men - Core City (Boston city poor) and College (Harvard undergraduates) - over the course of several decades. Vaillant (1995, pp. 124-63) found that a progression from a first drink to $\mathrm{AD}$, if it ever happens, takes between 3 and 15 years, and tends to be longer for the more educated men from the College sample. Alcohol abuse persists for between one and two decades and then declines at a stable rate. In the end, only a

\footnotetext{
${ }^{11}$ We test these differences by estimating a nested regression model for each indicator that includes, in addition to the full set of regression variables, their cross products with the gender dummy ( 0 for male twin pairs, 1 for female). The cross product of schooling and the gender dummy being significantly different from zero implies a statistically significant difference between schooling estimates for male and female twins. Since there are two variables that need instrumenting in the nested equation schooling and its interaction with gender there are also two instruments: twin reported schooling and its interaction.
} 
Table 6. Means of problem drinking indicators by gender and age group

\begin{tabular}{|c|c|c|c|c|c|c|c|c|}
\hline \multirow[b]{2}{*}{ Indicator } & \multicolumn{4}{|l|}{ Men } & \multicolumn{4}{|c|}{ Women } \\
\hline & $\leq 30$ & 3140 & 4150 & $\geq 51$ & $\leq 30$ & 3140 & 4150 & $\geq 51$ \\
\hline Drinks last week & 13.544 & 11.154 & 10.726 & 11.215 & $\overline{5} .858$ & 5.284 & 6.008 & $\overline{5} .663$ \\
\hline $\begin{array}{l}\text { Maximum drinks per } \\
\text { day typical week }\end{array}$ & 5.849 & 4.896 & 4.446 & 3.436 & 3.405 & 2.843 & 2.542 & 2.193 \\
\hline AD & 0.283 & 0.271 & 0.252 & 0.162 & 0.101 & 0.074 & 0.089 & 0.043 \\
\hline Five shot & 4.808 & 4.557 & 4.374 & 4.107 & 3.098 & 3.068 & 2.951 & 3.120 \\
\hline CAGE & 1.736 & 1.554 & 1.481 & 0.964 & 1.145 & 1.005 & 0.737 & 0.535 \\
\hline $\begin{array}{l}\text { Inability to reduce/stop } \\
\text { drinking }\end{array}$ & 0.906 & 0.718 & 0.629 & 0.423 & 0.399 & 0.384 & 0.324 & 0.293 \\
\hline $\begin{array}{l}\text { Behavioural problems } \\
\text { caused by drinking }\end{array}$ & 1.406 & 1.074 & 0.899 & 0.472 & 0.435 & 0.316 & 0.296 & 0.297 \\
\hline $\begin{array}{l}\text { Health problems caused } \\
\text { by drinking }\end{array}$ & 0.318 & 0.197 & 0.199 & 0.074 & 0.142 & 0.081 & 0.071 & 0.038 \\
\hline
\end{tabular}

Table 7. The effects of an extra year of schooling on age started to drink and past (1980) alcohol intake

\begin{tabular}{|c|c|c|c|c|}
\hline \multirow[b]{2}{*}{$\begin{array}{c}\text { Dependent } \\
\text { variable }\end{array}$} & \multicolumn{2}{|l|}{ Men } & \multicolumn{2}{|l|}{ Women } \\
\hline & $\begin{array}{l}\text { Simple } \\
\text { regression }\end{array}$ & $\begin{array}{l}\text { Twin } \\
\text { differences } \\
\text { (schooling } \\
\text { instrumented) }\end{array}$ & $\begin{array}{l}\text { Simple } \\
\text { regression }\end{array}$ & $\begin{array}{l}\text { Twin } \\
\text { differences }\end{array}$ \\
\hline Age started to drink & $\begin{array}{l}0.149 * * * \\
(0.055)\end{array}$ & $\begin{array}{c}0.029 \\
(0.119)\end{array}$ & $\begin{array}{l}0.537 * * * \\
(0.054)\end{array}$ & $\begin{array}{c}0.169 \\
(0.157)\end{array}$ \\
\hline Past intake & $\begin{array}{l}0.573^{* *} \\
(0.273)\end{array}$ & $\begin{array}{c}0.382 \\
(0.793)\end{array}$ & $\begin{array}{c}0.085 \\
(0.087)\end{array}$ & $\begin{array}{c}0.383 \\
(0.271)\end{array}$ \\
\hline
\end{tabular}

Note: $* * * p<0.01, * * p<0.05$

quarter of alcohol abusers remain so by age 60 , while the rest abstain from alcohol completely or die, or, in a small number of cases, return to 'safe' drinking.

To relate our data to Vaillant's (1995) findings, Table 6 reports the means of our main (problem) drinking indicators by age groups: 30 or younger, $31-40,41-50$ and 51 or older. We do observe a pattern in alcohol intake and the incidence of alcoholrelated problems by age group which is consistent, though not identical, with the life cycle of alcoholism as described by Vaillant (1995). (It must be noted that, unlike Vaillant, we cannot control for secular trends in alcohol consumption co-shaping the observed age patterns of alcoholism.) While the total weekly intake is fairly stable, the peak intake and the associated problems are at their highest in the age group 30 or younger, gradually abating in older age groups before falling dramatically in the age group 51 or older. Evidently, even though the underlying questions for the problem drinking symptoms refer to the entire lifetime, the respondents have limited recall of the events of distant past.

The presence of the life cycle of alcoholism in our data may affect the robustness of our regression estimates to interpretations alternative to the effect of schooling. Suppose schooling does not affect the likelihood of alcoholism but does delay its onset. Then the observed differences in problem drinking symptoms between the twins at a given point in time will be attributed to schooling differences, whereas in fact they are due to different phases of the life cycle of alcoholism. To examine whether there is evidence for schooling affecting the life cycle of alcoholism, we estimate the effect of schooling on (i) age when started to drink and (ii) past (1980) alcohol intake. The first effect will measure the ability of schooling to delay the start of the alcoholism life cycle, and the second will measure the extent to which schooling affects the length of the life-cycle phase before the development of alcoholism. It turns out (Table 7) that neither effect is significant once we take twin differences, implying that our earlier estimates are not materially affected by the life-cycle bias. A question might still be asked, however, as to whether the effect of schooling is specific to a certain stage in the alcoholism life cycle. To answer this question, we run our basic regressions on subsamples of twins younger and older than 40 in 1988 (the median age in 
Table 8. The effects of an extra year of schooling by age group

\begin{tabular}{lccccc}
\hline & Men & \multicolumn{3}{c}{ Women } \\
\cline { 2 - 3 } \cline { 5 - 6 } $\begin{array}{l}\text { Dependent } \\
\text { variable }\end{array}$ & Age $\leq 40$ & Age $>40$ & & Age $\leq 40$ & Age $>40$ \\
\hline AD & 0.029 & $0.070^{* *}$ & 0.010 & $0.068^{* *}$ \\
& $(0.031)$ & $(0.033)$ & & $(0.017)$ & $(0.032)$ \\
Five shot & $0.367 *$ & 0.171 & & 0.086 & 0.059 \\
& $(0.206)$ & $(0.176)$ & & $(0.116)$ & $(0.221)$ \\
CAGE & $0.224 * *$ & 0.060 & & 0.070 & 0.014 \\
& $(0.093)$ & $(0.084)$ & & $(0.057)$ & $(0.063)$ \\
Inability to & $0.137^{*}$ & 0.103 & & 0.036 & $0.154 *$ \\
stop/reduce & $(0.081)$ & $(0.070)$ & & $(0.039)$ & $(0.080)$ \\
Behavioural & 0.157 & 0.096 & & $0.082^{*}$ & 0.022 \\
problems & $(0.107)$ & $(0.095)$ & $(0.050)$ & $(0.104)$ \\
Health & $0.103^{* *}$ & $0.114 * * *$ & 0.029 & 0.039 \\
problems & $(0.048)$ & $(0.041)$ & $(0.022)$ & $(0.049)$ \\
\hline
\end{tabular}

Note: ${ }^{* * *} p<0.01, * * p<0.05, * p<0.1$.

the sample). The results, reported in Table 8 show that the effect of schooling on problem drinking is somewhat stronger for younger men and women. The AD score and health problems are two exceptions, presumably because they reflect the consequences of long-term alcohol abuse rather than more contemporary symptoms of it. However, the tendency of the respondents to forget past events (recall Table 6) makes further interpretation of these findings difficult.

\section{Reverse causality}

Another challenge to the interpretation of our results as evidence for the causal effect of schooling on problem drinking is the possibility of reverse causation, whereby excessive drinking causes people to attain less schooling than they would otherwise have attained. To address this possibility within the limits of our data, we exploit the variation in the age when started to drink between male twins once again. We have already demonstrated (Table 7) that the age when started to drink is unrelated to schooling once genetic influences have been isolated. This result enables us to proceed with relative ease to selecting a subsample for each sex in which individuals had already completed their education before they started to drink, so that drinking could not have affected their schooling attainment. This subsample is comprised of people whose age when started to drink exceeds their schooling by 6 years (six is the age when compulsory education in Australia begins). Individuals in each subsample are somewhat younger (39 - men, 38 - women) and less educated (11.3 men, 10.3 - women) than sample averages, but the
Table 9. The effects of an extra year of schooling for twins who started to drink after leaving education

\begin{tabular}{lcc}
\hline Dependent variable & Men & Women \\
\hline AD & $0.161^{* * *}$ & 0.007 \\
& $(0.058)$ & $(0.028)$ \\
Five shot & $0.558^{* *}$ & 0.215 \\
& $(0.282)$ & $(0.203)$ \\
CAGE & $0.240^{*}$ & 0.083 \\
& $(0.126)$ & $(0.073)$ \\
Inability to stop/reduce & $0.348^{* * *}$ & 0.030 \\
& $(0.11)^{* *}$ & $(0.066)$ \\
Behavioural problems & $0.323^{* *}$ & 0.025 \\
& $(0.160)$ & $(0.084)$ \\
Health problems & $0.234^{* *}$ & 0.014 \\
& $(0.068)$ & $(0.041)$ \\
\hline
\end{tabular}

Note: ${ }^{* * *} p<0.01, * * p<0.05,{ }^{*} p<0.1$.

average incidence of problem drinking symptoms is about the same as on the whole sample: men (women) average 0.25 (0.07) on $\mathrm{AD}, 4.55$ (2.85) on five-shot score, $1.33(0.74)$ on CAGE, and $0.19(0.09)$ on health problems due to drinking.

Table 9 reports estimated effects of 1 year of schooling on these subsamples. For men, the estimates are in fact larger than on the whole sample, which is consistent with our findings for younger men (the previous section) and men with secondary education or less (the next section). For instance, an extra year of schooling reduces the probability of AD by 0.16 , the number of behavioural problems by 0.32 , and health problems by 0.23. Admittedly, the assumption that the individuals' schooling went uninterrupted by the onset of drinking, implicit in the selection rule for this sample, is a limitation that must be observed. Still, the fact that we find a negative effect of schooling on problem drinking for those who could not have left education because of drinking implies that reverse causality cannot explain our main results for men. There are no significant effects of schooling on the female subsample, implying that the few significant results found for women earlier are sensitive to the assumption on the direction of causality from schooling to problem drinking.

\section{Effects for subgroups}

We now zoom in on particular subgroups in our sample of twins which we define according to the following criteria: (i) positive parental history of problem drinking (father's or mother's alcohol consumption in the top quartile of distribution), (ii) level of education not exceeding high school, and (iii) difference in schooling between twins not exceeding 3 years. The regression results are reported in Table 10 . 


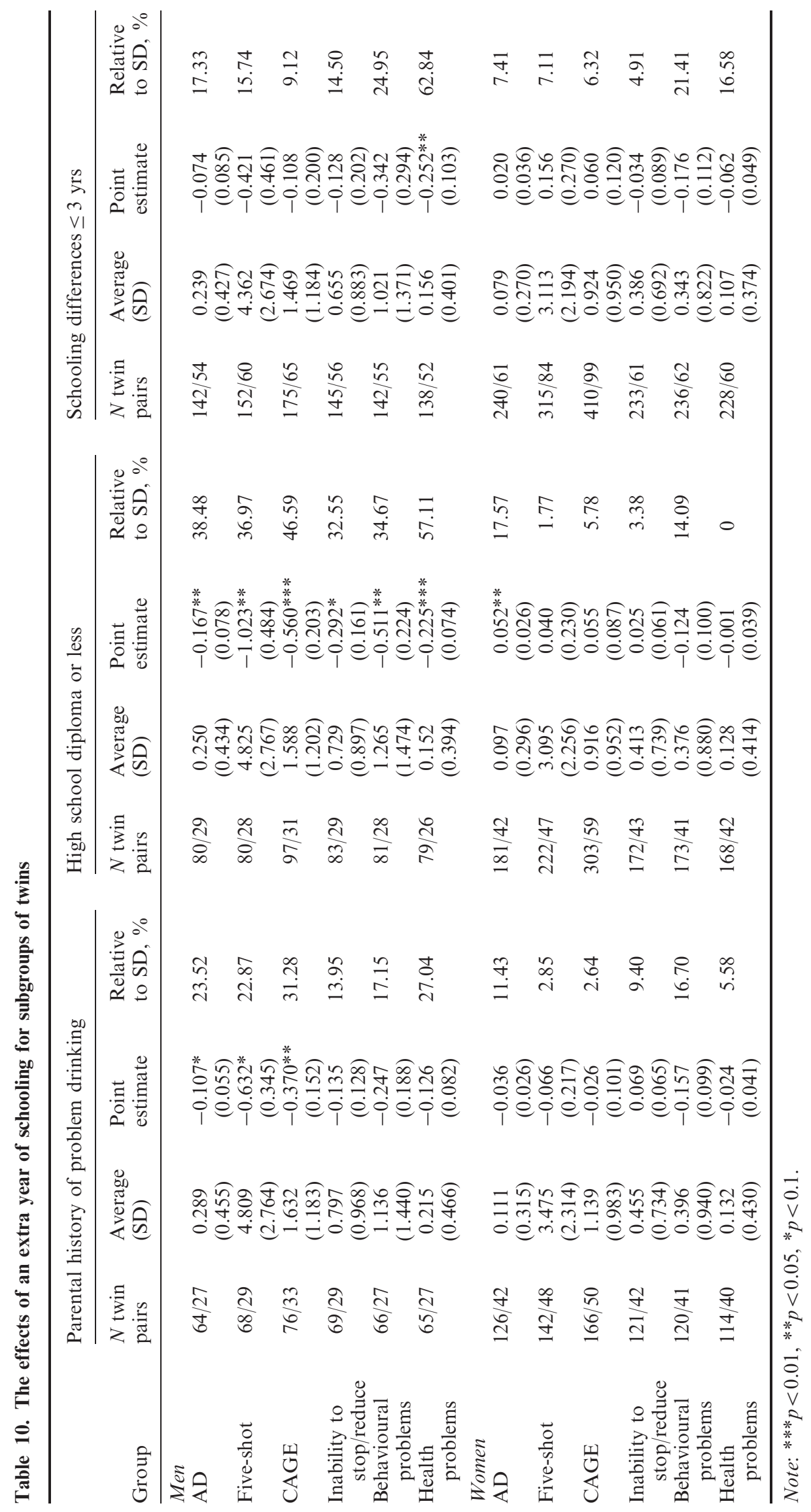


The subgroup with a parental history of problem drinking could be targeted for educational interventions because of its exposure to bad parental habits, as well as inheritability of alcoholism (Knopik et al., 2004). Indeed, individuals in this subgroup report higher average occurrence of problem drinking symptoms. At the same time, it is not clear whether the soft power of education can make a difference for this group. We find, however, that for men the estimates for schooling mostly exceed those obtained on the entire sample (Table 4) both in absolute magnitude and relative to the sample SD. (Health problems and inability to stop/reduce drinking are exceptions, but even then the differences are not significant given the estimates' SEs.) Our findings thus suggest that targeting men with a parental history of problem drinking could be even more efficient than giving extra education to all. The results for female twins with a parental history of drinking are not much different from the entire sample, except that the effect of schooling on AD is now negative, albeit insignificant.

Turning to the subgroup of twins with a highschool diploma or less, it may be argued that skills and knowledge helping to resist problem drinking are quite general and therefore are taught earlier in life. One could then hypothesize that problem drinking effects of early schooling are highest. Bringing this hypothesis to the empirical test, we find much larger effects for male twins with a high-school diploma or below, the subgroup otherwise similar to the whole sample. ${ }^{12}$ Put differently, an extra year of schooling in secondary education (high school or below) brings larger benefits in terms of reducing male problem drinking than does an extra year in further education. The results for the female subsample are, again, in line with the overall results for women, and remain quite different from the results for men. Interestingly, the positive effect of schooling on the likelihood of developing $\mathrm{AD}$ is stronger for this group than for the rest of the female sample. We do not have an explanation for this result, but since is it not stable across samples we are not inclined to conclude that schooling does increase the likelihood of $\mathrm{AD}$ for women.

Finally, we rerun our analysis on the subgroups of male and female twins for whom the difference in schooling does not exceed 3 years with the aim of testing the sensitivity of our results to removing large differences in the years of schooling which may not be exogenous. These subgroups make up about $80 \%$ of the original sample for men and $90 \%$ for women. The point estimates remain broadly similar to those obtained on the entire sample. However, since the share of twins with zero difference in schooling in the sample is now greater, there is a marked increase in the SDs of the schooling coefficients, with schooling remaining significant only for the health problems indicator. It is thus the effect of schooling on health problems experienced by men that is the most robust finding of our study. The effect of an extra year of schooling relative to the health problems indicator's $\mathrm{SD}(63 \%)$ is bigger than on the entire male sample. Note, however, that the present subsample features a greatly reduced variation in schooling: 1 year compared to 1.6 on the entire sample. In fact, the estimated effects of one SDs increase in the years of schooling relative to the SD in the health problems variable on the two samples are more comparable: $63 \%$ versus $48 \%$.

\section{Limitations}

A word of caution in interpreting our results is in order. First, there are general concerns over our data's representativeness of general population, also mentioned in the earlier studies (Knopik et al., 2004; Webbink et al., 2010), such as over-representation of higher-educated individuals and predominantly European ancestry of the respondents, which may influence metabolism and hence the occurrence of problem drinking symptoms. Second, there are concerns specific to our method and results. For instance, we find, intriguingly, that with age people tend to report fewer, not more, problem drinking symptoms ever happened to them in a lifetime, and that the effect of schooling wears out for some indicators and stays the same or increases for the other, both of which findings require explanation. While we have taken some steps towards addressing the issues of reverse causality and lifecycle bias, we have approached, but not quite achieved, an ideal natural experiment setting in which otherwise identical individuals would be administered different amounts of schooling in the beginning and followed up over the course of time. In fact, since we cannot identify the source of variation in schooling within identical twin pairs, its exogeneity remains a maintained assumption which we could only partially relax by restricting our sample to 'small' differences in schooling for which this assumption seems more credible.

\footnotetext{
${ }^{12}$ The only exception is the health problem count which average, 0.152 , is lower than on the whole sample (0.221). This cannot be explained by age differences between subgroups, since those with high school diploma are about the same age on average as those with higher education.
} 
Table 11. The effects of an extra year of schooling by frequency of contact between twins

\begin{tabular}{|c|c|c|c|c|}
\hline \multirow[b]{2}{*}{$\begin{array}{c}\text { Dependent } \\
\text { variable }\end{array}$} & \multicolumn{2}{|l|}{ Men } & \multicolumn{2}{|l|}{ Women } \\
\hline & $\begin{array}{l}\text { More } \\
\text { than } \\
\text { once } \\
\text { a year }\end{array}$ & $\begin{array}{l}\text { Less } \\
\text { than } \\
\text { once } \\
\text { a year }\end{array}$ & $\begin{array}{l}\text { More } \\
\text { than } \\
\text { once } \\
\text { a year }\end{array}$ & $\begin{array}{l}\text { Less } \\
\text { than } \\
\text { once } \\
\text { a year }\end{array}$ \\
\hline $\mathrm{AD}$ & $\begin{array}{c}0.055^{*} \\
(0.032)\end{array}$ & $\begin{array}{c}0.040 \\
(0.031)\end{array}$ & $\begin{array}{c}0.030 \\
(0.020)\end{array}$ & $\begin{array}{c}0.015 \\
(0.025)\end{array}$ \\
\hline Five shot & $\begin{array}{c}0.259 \\
(0.169)\end{array}$ & $\begin{array}{c}0.299 \\
(0.230)\end{array}$ & $\begin{array}{c}0.158 \\
(0.134)\end{array}$ & $\begin{array}{c}0.038 \\
(0.154)\end{array}$ \\
\hline CAGE & $\begin{array}{c}0.135^{*} \\
(0.082)\end{array}$ & $\begin{array}{c}0.159 \\
(0.099)\end{array}$ & $\begin{array}{l}0.133^{* *} \\
(0.057)\end{array}$ & $\begin{array}{c}0.046 \\
(0.061)\end{array}$ \\
\hline $\begin{array}{l}\text { Inability to } \\
\text { stop/reduce }\end{array}$ & $\begin{array}{c}0.113^{*} \\
(0.068)\end{array}$ & $\begin{array}{c}0.139 \\
(0.096)\end{array}$ & $\begin{array}{c}0.024 \\
(0.046)\end{array}$ & $\begin{array}{c}0.049 \\
(0.056)\end{array}$ \\
\hline $\begin{array}{c}\text { Behavioural } \\
\text { problems }\end{array}$ & $\begin{array}{c}0.135 \\
(0.097)\end{array}$ & $\begin{array}{c}0.127 \\
(0.116)\end{array}$ & $\begin{array}{c}0.082 \\
(0.061)\end{array}$ & $\begin{array}{c}0.062 \\
(0.063)\end{array}$ \\
\hline $\begin{array}{l}\text { Health } \\
\text { problems }\end{array}$ & $\begin{array}{l}0.100 * * \\
(0.040)\end{array}$ & $\begin{array}{l}0.113^{* *} \\
(0.056)\end{array}$ & $\begin{array}{c}0.006 \\
(0.026)\end{array}$ & $\begin{array}{c}0.033 \\
(0.031)\end{array}$ \\
\hline
\end{tabular}

Note: $* * p<0.05, * p<0.1$.

Finally, there is a possibility that twins' behaviours affect one another. For instance, the co-twin of an alcoholic might reduce his alcohol consumption as a behavioural response, in which case the effect of schooling will be overestimated. ${ }^{13}$ This possibility does not lend itself to a rigorous test, since 'peer effects' between twins cannot be identified. However, we find that the averages of alcohol intake and associated problems reported by siblings of alcoholic twins are higher, not lower, than those of siblings of nonalcoholic twins. We also find (Table 11) that, while the strength of peer effects should presumably depend on the frequency of contact, the estimates for the effect of schooling are essentially the same for men who have seen each other more and less often than once a year over the last 8 years. Thus, while acknowledging the possibility of peer effects among twins as another limitation of our study design, we fail to obtain evidence for their actual presence in our male sample. Turning to female twins, we do observe bigger schooling effects for twins who see each other more frequently (though most of them still remain insignificant), which is consistent with twins' negative response to their co-twin's drinking. Clearly, problem drinking by women differs from men's and needs a separate model to be described and analysed better.

\section{Conclusions}

In this study, we have examined whether the negative correlation between schooling and alcohol intake frequently observed in the 'health gradient' literature can be taken as evidence that more schooling causes less drinking. Using data from identical twins has enabled us to exploit the variation in schooling free from genes or family background, both of which factors may affect intake. We have found that schooling and alcohol intake are not directly related; rather, it is the unobservables that shape the correlation between the two. What schooling does affect is men's ability to enjoy alcohol without adverse consequences to self and others. The most robust evidence we have found is for the effect of schooling on the number of health problems due to drinking: 0.14 fewer with an extra year. This effect persists in different specifications, surviving a variety of robustness checks. Our second most important finding, though somewhat less robust to changes in identifying assumptions, is that an extra year of schooling reduces the likelihood of developing AD by $6 \%$. Both effects are important quantitatively and make up appreciable fractions of the respective symptoms' SDs.

Our study contributes to the health gradient literature in general, and the problem drinking literature in particular, by linking schooling to several problem drinking indicators, and by addressing the issues of measurement error in schooling and heterogeneity in its effects on different subgroups. Addressing these issues has important implications

\footnotetext{
${ }^{13}$ Suppose a problem drinking indicator depends not only on schooling but also the same problem drinking indicator of the cot win. Then Equation 1 will read (skipping controls for simplicity)
}

$$
\text { y } \quad \beta s+\delta y^{\prime}+u
$$

where $y^{\prime}$ is the problem drinking indicator of the co twin. Twin differencing results in

$$
\Delta y \quad \beta \Delta s \quad \gamma \Delta y+\Delta u
$$

which can be rewritten as

$$
\Delta y \quad \frac{\beta}{[1+\gamma]} \Delta s+\frac{1}{[1+\gamma]} \Delta u
$$

If $\delta$ is negative, the impact of schooling on alcoholism will be overestimated. We are especially grateful to the anonymous referee for presenting this point to us. 
for assessing policies to reduce problem drinking through education. Thus, comparing estimates in columns (2) and (3) of Table 4 shows that failure to take measurement error in schooling into account will result in overlooking much of its effect. It is therefore recommended to examine survey data for the presence of measurement error and implement a robust estimator such as the one introduced in Ashenfelter and Krueger (1994), or, failing this, to apply an errors-in-variables estimator with a well-gauged reliability ratio ( 0.8 in our data). Turning to the issue of heterogeneity, our finding that the effects of schooling vary by level of education and the presence or absence of parental history of problem drinking suggest efficiency gains from targeted educational interventions.

Advocating such interventions would of course require more research than we have done here. First, the effect of schooling on problem drinking by women is significantly different from men's and merits a separate inquiry. Second, more research is needed to calculate the implied benefits of schooling in terms of reducing the costs of alcohol abuse. Extra education is unlikely to be justified on the basis of reducing problem drinking alone, nor has it been featured prominently among ways to cope with problem drinking as yet. However, given the lifelong consequences of the habit, the one-off costs of keeping individuals from risk groups in school may be worth paying.

\section{Acknowledgements}

We thank the anonymous referee for the comments which have undoubtedly improved the quality of this article. Our research has benefitted from the comments by Erik Plug, Marc Frenette and the participants of the Canadian Economic Association's 2010 annual meeting, and from the early work done by Joeri Gorter who died, tragically, in October 2008. Part of this article was written while Nick Zubanov worked at CPB Netherlands Bureau of Economic Policy Analysis and Tilburg University. He acknowledges the support from these institutions.

\section{References}

APA (2000) Diagnostic and Statistical Manual of Mental Disorders DSM IV TR, 4th edn, American Psychiatric Association, Washington, DC.

Ashenfelter, O. and Krueger, A. (1994) Estimates of the economic return to schooling froma new sample of twins, American Economic Review, 84, 115773.
Babor, T., Higgins Biddle, J., Saunders, J. and Monteiro, M. (2001) The Alcohol Use Disorders Identification Test Guidelines for Use in Primary Care, World Health Organization. Available at http://whqlibdoc.who.int/ hq/2001/WHO_MSD_MSB_01.6a.pdf (accessed 6 September 2011).

Baltagi, B. and Griffin, J. (1995) A dynamic model for liquor: the case for pooling, Review of Economics and Statistics, 77, 54554.

Behrman, J. and Rosenzweig, M. (2002) Does Increasing Women's Schooling Raise the Schooling of the Next Generation?, American Economic Review, 92, 32334.

Behrman, J. and Taubman, P. (1989) Is schooling 'mostly in the genes'? Nature nurture decomposition using data on relatives, Journal of Political Economy, 97, 142546.

Black, S., Devereux, P. and Salvanes, K. (2007) From the cradle to the labor market? The effect of birth weight on adult outcomes, Quarterly Journal of Economics, 122, 40939.

Bonjour, D., Cherkas, L., Haskel, J., Hawkes, D. and Spector, T. (2003) Returns to education: evidence from UK twins, American Economic Review, 93, 1799812.

Collins, D. and Lapsley, H. (2008) The avoidable costs of alcohol abuse in Australia and the potential benefits of effective policies to reduce the social costs of alcohol, Australian Government Department of Health and Ageing Monograph Series No. 70.

Cutler, D. M. and Glaeser, E. (2005) What explains differences in smoking, drinking, and other health related behaviors? American Economic Review, 95, 23842.

Cutler, D. M. and Lleras Muney, A. (2006) Education and health: evaluating theories and evidence, NBER Working Paper No. 12352.

Droomers, M., Schrijvers, C. and Mackenbach, J. (2004) Educational differences in starting excessive alcohol consumption: explanations from the longitudinal GLOBE study, Social Science and Medicine, 58, 202333.

Furnée, C. A., Groot, W. and Maassen van den Brink, H. (2008) The health effects of education: a meta analysis, European Journal of Public Health, 18, 41721.

Häkkinen, U., Järvelin, M. R., Rosenqvist, G. and Laitinen, J. (2006) Health, schooling and lifestyle among young adults in Finland, Health Economics, 15, 120116

Harwood, H. (2000) Updating estimates of the economic costs of alcohol abuse in the United States: estimates, update methods, and data, Report prepared by The Lewin Group for the National Institute on Alcohol Abuse and Alcoholism. Available at http://pubs. niaaa.nih.gov/publications/economic 2000/index.htm (accessed 6 September 2011).

Heath, A., Bucholz, K., Madden, P., Dinwiddie, S., Slutske, W., Bierut, L., Statham, D., Dunne, M., Whitfield, J. and Martin, N. (1997) Genetic and environmental contributions to alcohol dependence risk in a national twin sample: consistency in findings for women and men, Psychological Medicine, 27, 138196.

Kenkel, D. (1991) Health behavior, health knowledge, and schooling, Journal of Political Economy, 99, 287305.

Knop, J., Penick, E. C., Jensen, P., Nickel, E. J., Gabrielli, W. F., Mednick, S. A. and Schulsinger, F. (2003) Risk 
factors that predicted problem drinking in Danish men at age thirty, Journal of Studies on Alcohol, 64, 74555.

Knopik, V., Heath, A., Madden, P., Bucholz, K., Slutske, W., Nelson, E., Statham, D., Whitfield, J. and Martin, N. (2004) Genetic effects on alcohol dependence risk: re evaluating the importance of psychiatric and other heritable risk factors, Psychological Medicine, 34, 151930.

Lopez, A., Mathers, C., Ezzati, M., Jamison, D. and Murray, C. (Eds) (2006) Global Burden of Disease and Risk Factors, The World Bank Group, Washington, DC.

Maqsud, M. (1993) Relationships of some personality variables to academic attainment of secondary school pupils, Educational Psychology, 13, 1118.

Mayfield, D., McLeod, G. and Hall, P. (1974) The CAGE questionnaire: validation of a new alcoholism screen ing instrument, American Journal of Psychiatry, 131, 11213.

Miller, P., Mulvey, C. and Martin, N. (1995) What do twins studies reveal about the economic returns to educa tion? A comparison of Australian and US findings, American Economic Review, 85, 58699.

NAO (2008) Reducing alcohol harm: health services in England for alcohol misuse, UK National Audit Office. Available at http://www.nao.org.uk/ publications/0708/reducing_alcohol_harm.aspx (accessed 6 September 2011).
Park, C. and Kang, C. (2008) Does education induce healthy lifestyle? Journal of Health Economics, 27, 151631.

Preuss, U., Johann, M., Fehr, C., Koller, G., Wodarz, N., Hesselbrock, V., Wong, W. M. and Soyka, M. (2009) Personality disorders in alcohol dependent individuals: relationship with alcohol dependence severity, European Addiction Research, 15, 18895.

Seppä, K., Lepistö, J. and Sillanaukee, P. (1998) Five shot questionnaire on heavy drinking, Alcoholism: Clinical and Experimental Research, 22, 178891.

Sharpe, D., Abdel Ghany, M., Kim, H. Y. and Hong, G. S. (2001) Alcohol consumption decisions in Korea, Journal of Family and Economic Issues, 22, 724.

Slutske, W., Heath, A., Madden, P., Bucholz, K., Statham, D. J. and Martin, N. (2002) Personality and the genetic risk for alcohol dependence, Journal of Abnormal Psychology, 111, 12433

Vaillant, G. E. (1995) The Natural History of Alcoholism Revisited, Harvard University Press, Cambridge, MA.

van Oers, J., Bongers, I., van de Goor, L. and Garretsen, H. (1999) Alcohol consumption, alcohol related pro blems, problem drinking, and socioeconomic status, Alcohol and Alcoholism, 34, 7888.

Webbink, H., Martin, N. and Visscher, P. (2010) Does education reduce the probability of being overweight? Journal of Health Economics, 29, 2938. 